\title{
Sobre "guetos" e "rótulos": tensões no mercado GLS na cidade de São Paulo*
}

\author{
Isadora Lins França**
}

\begin{abstract}
Resumo
Este artigo, apoiado em observação etnográfica, fontes documentais e entrevistas, enfoca a constituição de um circuito GLS na cidade de São Paulo desde a década de 1990, bem como uma disposição de se passar ao largo de categorias relacionadas a sexualidade na definição de espaços de consumo e sociabilidade, abraçada por um público que poderia ser definido pela categoria "modernos". A abordagem desses processos está ancorada em perspectivas teóricas que observam o caráter contingencial e performativo da constituição de identidades, bem como consideram os processos relacionados ao consumo como sendo fundamentalmente um ato social.
\end{abstract}

Palavras-chave: Sexualidade, Estilos de Vida, Consumo, Homossexualidade, Identidade.

\footnotetext{
* Recebido para publicação em fevereiro 2007, aprovado em maio de 2007. O presente texto é fruto do trabalho desenvolvido para a minha dissertação de mestrado (França, 2006a), sob orientação do Prof. Dr. Júlio Assis Simões. O artigo também se beneficiou das leituras atentas e comentários de Richard Miskolci, Anna Paula Vencato, Regina Facchini e Júlio Assis Simões. Devo dizer, porém, que as escolhas teóricas e caminhos aqui percorridos são de minha inteira responsabilidade.

** Doutoranda em Ciências Sociais pela Universidade Estadual de Campinas. isadora.lins@uol.com.br
} 
Sobre "guetos" e "rótulos"

On "Ghettos" and "Labels":

Tensions in the Gay Market in Sao Paulo

\begin{abstract}
This article, cased on ethnographic research, documental sources and interviews, focuses on the formation of a gay and lesbian market in São Paulo since the 1990's. It analyses a disposition to escape to categories related to sexuality in the definition of spaces of sociability and consumption, which are supported by a public that could be called of "modern" people. The analysis of these processes is founded on theoretical perspectives that assume the contingent and performative character of identity construction, as well as considering the processes related to consumption as basically a social act.
\end{abstract}

Key Words: Sexuality, Lifestyles, Consumption, Homosexuality, Identity. 
As abordagens que procuram desnaturalizar os domínios relativos à sexualidade abrem um novo campo para as ciências sociais, descortinando a possibilidade de análise de processos anteriormente tidos como dados. Além disso, abre-se a possibilidade de se pensar questões relativas à sexualidade de modo mais amplo, já que não se trata mais de algo pertencente apenas à esfera da intimidade e do privado, nem de questões restritas à psicanálise e psicologia, posto que tampouco estamos tratando somente de aspectos individuais e processos psíquicos, o que permite que conexões que se dão entre sexualidade $e$ economia, política e religiosidade, por exemplo, possam ser traçadas (Piscitelli et alii, 2005). Gamson e Moon (2004) pontuam a influência da teoria queer na direção de ampliar o escopo das abordagens relacionadas à sexualidade nas ciências sociais, contribuindo decisivamente a partir de três perspectivas: o estudo de relações de poder que envolvem a sexualidade e a sua conexão com áreas que tradicionalmente se imaginava estarem afastadas do campo da sexualidade; o empreendimento de análises que consideram as interseccionalidades entre diferentes eixos de diferenciação; e a exploração das relações entre sexualidade e economia política à luz de recentes transformações do mercado.

Inspirada em tais perspectivas, procuro articular neste artigo uma discussão a respeito das relações entre sexualidade, consumo, estilo de vida e classe, tomando como foco aspectos relacionados ao mercado direcionado a homossexuais em São Paulo. Esse mercado segmentado torna-se um campo relevante para a reflexão acerca da construção de identidades coletivas relacionadas à sexualidade, considerando que produz diferentes categorias em torno do que é "ser homossexual", e da sexualidade de forma geral, e faz circular referências e imagens identitárias ${ }^{1}$ acerca dos possíveis estilos ligados à sexualidade.

1 Sobre a noção de imagens identitárias, ver Gontijo, 2005. 
Sobre "guetos" e "rótulos"

Tal processo só pode ser colocado como objeto de reflexão se tivermos em mente que as identidades não existem por si só, não possuem um conteúdo auto-idêntico capaz de atuar como descritivo dos sujeitos que pretendem nomear e que a construção de identidades se dá por meio de um mecanismo de diferenciação num campo potencialmente ilimitado, operando mediante exclusões que lhes são intrinsecamente características (Butler, 2003). Essas discussões já vinham se delineando nos estudos de gênero desde finais da década de 1980, como resultado da articulação de mulheres negras e lésbicas no movimento e teoria feminista, que se posicionavam de forma a expor a fragilidade de um uso e compreensão universais da categoria "mulher" e o entrecruzamento de pertencimentos específicos (raça, classe, sexualidade, entre outros) na produção de diferentes subjetividades (Haraway, 2004).

Procuro abordar as questões trazidas neste artigo sob uma perspectiva que ressalta o caráter performativo e contingente da construção de identidades coletivas, característica de um corpo teórico que vem sendo desenvolvido nas áreas de gênero $e$ sexualidade desde a década de 1990, retomando o trabalho de Foucault (1979) para a constituição de uma crítica à afirmação de identidades baseadas num sujeito pré-discursivo. ${ }^{2}$ Esse corpo teórico, que talvez faça parte do que se denomina amplamente de queer theory ${ }^{3}$, emerge diferenciando-se e mesmo questionando a

2 Cabe lembrar que, embora o trabalho de Foucault tenha sido amplamente retomado pelos estudos de gênero e sexualidade, determinados aspectos de sua obra também foram objeto de análise crítica, especialmente no que concerne a momentos em que o autor deixa margens à compreensão dos corpos e prazeres como pré-discursivos. Ver Butler, 2003b.

3 É tarefa inglória e possivelmente até indesejável definir claramente a noção de "queer theory". O termo "queer" vem sendo utilizado de inúmeras maneiras: seja definindo o sujeito político de um movimento marcado pela coalizão de identidades que reconhecem a si mesmas como fora da norma ou sugerindo um campo de produção intelectual, seja num uso mais popular, indicando simplesmente "homossexual". Para boa parcela das pessoas que reivindicam o termo, sua indefinição e a multiplicidade de significados a ele atrelados seriam 
produção associada aos gay and lesbian studies, que já encontravam-se bastante estabelecidos no campo intelectual norteamericano no que concerne aos debates sobre sexualidade $e$ gênero. Tal diferenciação, em parte, é decorrente da comum associação dos estudos relacionados à teoria queer a uma abordagem crítica frente à constituição de identidades, recusando um olhar caracterizado pela cristalização de identidades ou pelo estabelecimento da homossexualidade e heterossexualidade como duas esferas pouco permeáveis entre si. ${ }^{4}$

Por outro lado, da mesma maneira que se faz necessário um suporte teórico não essencialista a respeito da constituição de categorias identitárias, também é importante para a construção da análise aqui empreendida a adoção de uma perspectiva teórica que ultrapasse uma visão utilitarista frente aos processos relacionados ao consumo e ao mercado. Mary Douglas e Baron Isherwood (2004), num dos estudos pioneiros a tematizar o consumo, ressaltam que os bens e o consumo têm sido aspectos abstraídos da "totalidade do esquema social" pela economia e propõem que se retome a unidade deste sistema, mediante uma revisão geral dos fundamentos da teoria econômica. $\mathrm{O}$ ato de consumir foi relegado à ação de um indivíduo racional, que atua em interesse próprio, respondendo a necessidades individuais e sendo guiado por parâmetros racionais de custo/benefício. A prática do consumo permaneceria, então, fechada à análise das ciências sociais, não problematizada, já que sob ela jaz uma inquestionável decisão racional e evidente, ligando causas e fins.

$\mathrm{Na}$ direção, portanto, de traçar a possibilidade de uma perspectiva antropológica em relação ao consumo em oposição a perspectivas utilitaristas, persiste como ponto comum entre

efeitos positivos, que o tornariam resistente a um processo de normatização. Ver Jagose, 1996.

4 Dada a amplitude que caracteriza o que chamamos de "teoria queer", cabe ressaltar que também há abordagens que se reconhecem como parte desse campo, mas que apenas reeditam a mesma perspectiva dos gay and lesbian studies sob o nome de queer theory. Ver Giffney, 2004. 
Sobre "guetos" e "rótulos"

diferentes autores a conclusão de que o consumo é um ato social, através do qual partilhamos significados, produzimos diferenciações sociais e, conseqüentemente, construímos um universo inteligível. ${ }^{5}$ É simultaneamente, como define Miller (1995), uma prática no mundo e uma forma pela qual nós construímos nosso entendimento sobre nós mesmos no mundo. Como no debate a respeito das identidades coletivas e queer theory, quero aqui enfatizar que o consumo, portanto, torna-se uma arena na qual se constroem, afirmam e deslocam subjetividades.

É com base nos referenciais teóricos explicitados acima que se torna possível o desenvolvimento da análise a seguir, apoiada em observação etnográfica, análise de fontes documentais e entrevistas realizadas entre 2004 e 2006. No decorrer da análise, procuro empreender uma reflexão a respeito da formação de um "mercado GLS" em São Paulo e de suas dinâmicas, relacionadas a constantes deslocamentos e reacomodações de categorias identitárias e de produção de subjetividades no âmbito desse mercado.

Do "gueto" ao GLS

Desde meados da década de 1990, o que se conhecia como o "gueto" homossexual começa a se transformar num mercado mais sólido, expandindo-se de uma base territorial mais ou menos definida para uma pluralidade de iniciativas, que não deixam de comportar um circuito de casas noturnas, mas que também envolve, hoje, o estabelecimento de uma mídia segmentada, festivais de cinema, agências de turismo, livrarias, canais de TV a cabo, inúmeros sites, lojas de roupas, entre outros.

${ }^{5}$ Refiro-me a autores como Veblen, 1965; Douglas e Isherwood, 2004; Sahlins, 1979; Miller, 2000. 
Tal expansão vem acompanhada da proliferação de diversas categorias pautadas por estilos de vida - como barbies ${ }^{6}$ ursos $^{7}$ e coroas $^{8}$ - e de uma crescente segmentação de espaços de consumo destinados a cada uma delas. A segmentação de espaços destinados ao público homossexual acontece simultaneamente a um processo de multiplicação de identidades no interior do movimento GLBT: além das grandes categorias de gays, lésbicas, bissexuais, travestis e transexuais assumidas pelo movimento homossexual, emergem também subgrupos, incentivados pela proliferação de fóruns e listas de discussão na internet $e$ pertencentes principalmente ao segmento dos gays (grupos de advogados gays, judeus gays, adolescentes gays, surdos gays, etc.).

A segunda metade da década de 1990 traz outras mudanças consideráveis para o movimento GLBT (de Gays, Lésbicas, Bissexuais, Travestis e Transexuais): o pânico em relação à aids se amenizara, ao mesmo tempo em que avançava a eficácia dos medicamentos anti-retrovirais, e a idéia de "grupo de risco" deixava de ser utilizada, sendo aos poucos substituída por "comportamento de risco". É de fundamental importância que consideremos o surgimento da epidemia de HIV/aids para a compreensão do movimento na década de 1990: a epidemia que foi cercada por preconceito e estigmatização (Perlongher, 1987) também ocasionou uma abertura de caminhos para uma discussão pública a respeito da homossexualidade (Trevisan, 2000), uma ampliação do impacto de categorias médico-científicas no que diz respeito à sexualidade (Parker, 1994), e uma relação mais

\footnotetext{
${ }^{6}$ Homens de aparência viril, que exibem um corpo musculoso e trabalhado fisicamente.

${ }^{7}$ Homens que se identificam com códigos de masculinidade e valorizam atributos como a gordura e os pêlos, em contraposição às barbies.

8 Homens mais velhos, que também se identificam como maduros e freqüentam espaços destinados a esse público, assim como sites de encontros e festas em que são valorizados no mercado afetivo-sexual.
} 
Sobre "guetos" e "rótulos"

estreita do movimento homossexual com o Estado, transformando suas estratégias de organização. ${ }^{9}$

Do mesmo modo que teve um forte impacto no movimento, aparentemente a epidemia também influenciou sobremaneira os rumos do que se desenvolveria como um "mercado GLS" na década de 1990. Após um tempo de menor atividade, no período de pânico relacionado à aids, o circuito voltado para o público homossexual expande-se em São Paulo, e a mídia passa a abordar constantemente a homossexualidade e a sua própria visibilidade social, tida como crescente. Alguns artistas conhecidos da música popular passam a declarar-se como homossexuais sem maiores constrangimentos, e embora recusem o que consideram "levantar bandeiras", difundem uma imagem de que convivem bem com a homossexualidade e de que não precisam esconder sua orientação sexual. Também nas novelas de televisão, aparecem cada vez mais personagens homossexuais, "seja revisitando caricaturas e estereótipos, seja ensaiando uma aproximação a imagens mais 'modernas' de gays e lésbicas, e mesmo de travestis ou transexuais" (Simões e França, 2005:312). Essa "onda de visibilidade" também fortaleceu a expansão de um modelo de homossexualidade distinto do popular "bicha/bofe" e mais próximo das classificações médicas que passaram a orientar grande parte do movimento GLBT, pautadas mais pela orientação de desejo e práticas homossexuais para parceiros do mesmo sexo do que pela idéia de "atividade/passividade" e determinados comportamentos relacionados a convenções de gênero.

Tais considerações a respeito das mudanças trazidas pela aids no movimento GLBT e no mercado GLS não tratam apenas de um desfile de coincidências: julgo importante realçar o fato de que análises das iniciativas relacionadas ao mercado e mesmo ao comportamento de consumidores perdem em profundidade se interpretadas em separado de processos sociais mais amplos, e desconectadas de outros atores, como Estado e movimentos

9 Ver Galvão, 2000; Green, 2000; Facchini, 2005. 
sociais. Dessa maneira, é importante ressaltar que processos como um maior debate público a respeito da homossexualidade, o reforço de determinado modelo de classificação da homossexualidade, o fortalecimento de uma idéia de "orgulho" $e$ "visibilidade" e a proliferação de categorias identitárias não estão isolados um do outro, mas acontecem de forma imbricada entre si, abrangendo esferas como movimento GLBT, mercado GLS e Estado, que em diferentes momentos se aproximam ou se afastam uma das outras.

É nesse contexto que surge a categoria GLS. Se a idéia norte-americana de friendly refere-se a espaços freqüentados predominantemente por heterossexuais, nos quais homossexuais são bem vindos, a idéia brasileira de GLS segue o caminho inverso: o S da sigla indica "simpatizante", tendo como ponto de partida espaços freqüentados majoritariamente por homossexuais e revelando uma intenção de expandir as fronteiras do "gueto", quando propõe abarcar também consumidores que não se identificam como homossexuais, mas que de alguma forma participam desse universo. Um dos difusores do termo, assim define GLS:

GLS, para quem está voltando de outra galáxia, é uma expressão surgida no "Festival Mix Brasil" de 94, que abrevia Gays, Lésbicas e Simpatizantes. O objetivo é nomear um grupo de pessoas que se liga à cultura, moda $e$ música, que sai à noite e, principalmente, sem nenhum tipo de preconceito, independente da preferência sexual. ${ }^{10}$

O autor também identifica o uso do termo como uma atitude "mais democrática", que incorpora as lésbicas também e os simpatizantes, que "circulam no meio, mas não podem ser denominados gays" (Id. ib.). No rastro dessa "atitude" também verifica-se uma estratégia mais claramente comercial, como nota

${ }^{10}$ Fonte: FISCHER, André. Para ser mais democrático. Jornal Folha de S.Paulo, Revista da Folha, Coluna GLS, 15 de dezembro de 1996:54. 
Sobre "guetos" e "rótulos"

uma especialista em "negócios GLS": "É importante enfatizar que o S - de simpatizante - da sigla GLS, aumenta o número de consumidores do mercado". ${ }^{11}$

Quando surgiu, o termo GLS foi rapidamente associado a um público "moderno", interessado por arte, música, conectado à última moda e freqüentador da noite. Ato contínuo, uma recente cena noturna da cidade começou a ser identificada dessa maneira, já que personificava de alguma forma os significados colados à sigla e ao contexto em que foi criada. Essa cena tem origem no final da década de 1980, com o surgimento do "Nation Disco Club", marco inicial de algo que se denominou "cultura club" paulistana, que iria impulsionar um revigoramento do mercado direcionado a homossexuais e a sua expansão em direção aos Jardins, além de ganhar rápida visibilidade na mídia nacional. Embora esta cena não se caracterizasse inicialmente como "gay", é inegável que o universo relacionado à homossexualidade fosse parte fundamental. Além de atraírem o mesmo perfil de público ${ }^{12}$, os primeiros clubs e eventos tidos como GLS tinham ainda em comum uma definição mais ampla em relação à orientação sexual de seus consumidores habituais.

Outros estabelecimentos se seguiram ao "Nation Disco Club", atraindo a atenção da mídia pelos ares de novidade, exotismo e liberação sexual, como relata um dos agitadores dessa cena:

era uma fase de procura, de libertação, muito importante.

Os gays e drags iam lá, em grande quantidade e, como não

\footnotetext{
${ }^{11} \mathrm{http} / / /$ www.gaybrasil.com.br/mercadogls.asp?Categoria $=$ Mercado\&Codigo $=$ 1460. Acesso em março de 2005

${ }^{12} \mathrm{O}$ público congregado em torno do termo club poderia ser definido como vindo "de todas as procedências, pessoas com indumentária extravagante, avançada e ligada às últimas tendências da moda; um gosto musical eclético $e$ interessado pelas novidades de meados/final dos anos 80 ; não segregação de freqüentadores sob o ponto de vista da orientação sexual; mistura de artistas de diversas áreas; posições políticas progressistas" (Calil, 2000: 200).
} 
era uma casa fechada, o público pôde manter uma relação sincera com essa fatia da sociedade. E como a mídia estava de olho, o Massivo foi para os jornais, houve até programas de TV em cima do local. E isso só aconteceu porque nós tínhamos algo a dizer. ${ }^{13}$

Posteriormente, tais estabelecimentos foram definitivamente incorporados ao que se denominou circuito GLS.

A identificação dos espaços de consumo ligados ao público homossexual como GLS sem dúvida impulsionou a expansão desse mercado e possibilitou sua visibilidade para além do "gueto". Esse processo caminhou junto com a incorporação gradativa da categoria GLS ao cenário de lazer noturno da cidade e GLS passou a ser indicador não mais de uma atitude "moderna", perdendo os ares de contestação e novidade que a ela se agregaram logo que surgiu e passando a denominar qualquer casa noturna ou iniciativa do mercado dirigida a homossexuais. É importante notar que esse novo mercado GLS também absorveu os antigos espaços de sociabilidade homossexual de forma diferenciada. O seu desenvolvimento é atravessado por relações de poder que empurram "mais gordos", "mais velhos", pobres, negros, travestis, michês e "efeminados"/"masculinizadas" para os espaços marcados por um menor prestígio social e menor integração a circuitos globais. Seu caráter excludente surge com força quando olhamos para as pessoas nas pontas mais marginalizadas socialmente, às quais não é permitido exercer sequer o papel de consumidoras. O caso das travestis é emblemático: muitas vezes são barradas ou maltratadas em estabelecimentos destinados a homossexuais, evidenciando os limites de inclusão deste mercado segmentado (França, 2006b).

${ }^{13}$ Fonte: Giacomomini, Paulo; Lins, Pedro. Na cama com Mauro Borges. G Magazine, ano 1, nº 08, São Paulo, 1997:54. 
Sobre "guetos" e "rótulos"

Nem GLS, nem HT: "transcendendo o 'gueto'?"

Com a popularização da sigla GLS, a distinção entre um estabelecimento gay e "GLS", se é que um dia foi tão efetiva quanto gostariam os autores da sigla, perdeu-se bastante, e hoje é muito comum a utilização das duas denominações como sinônimos. Mesmo espaços nitidamente segmentados, como saunas gays, podem ser definidas como GLS, indicando que o termo passou a ter significados não previstos originalmente $e$ mesmo em oposição aos quais havia surgido.

Os espaços hoje tidos como GLS são freqüentados majoritariamente por pessoas que se relacionam com outras do mesmo sexo, causando inclusive polêmica algo considerado como uma "invasão" de heterossexuais - que também ganharam outra denominação além do "S", mais específica, como "HT" - nesses espaços. Em muitas boates, o público "HT" é bem vindo. Em outros casos, verifica-se uma resistência maior aos simpatizantes, com casas noturnas destinadas a gays chegando a cobrar entrada mais cara para mulheres (França, 2006a).

Têm surgido na noite paulistana, porém, espaços que procuram passar ao largo da discussão sobre a presença de heterossexuais ou homossexuais e que, se podem ser classificados como GLS por guias específicos e afins, prezam pela mistura do público e pela sua indefinição como forma de marcar uma diferença em relação a outros estabelecimentos do circuito. ${ }^{14} \mathrm{~A}$ casa noturna mais conhecida nessa linha é "A Lôca", boate localizada na Rua Frei Caneca. Herdeira direta da onda clubber

\footnotetext{
${ }^{14} \mathrm{O}$ punhado de estabelecimentos que atraem este tipo de público de forma mais estável espalha-se pela região da Cerqueira César, nas ruas Augusta, Frei Caneca e Bela Cintra, pelo centro antigo e pela Vila Madalena. Com exceção da boate "A Lôca", mais conhecida, costumam ser espaços não muito grandes, com pista de dança, bar e lugar para shows. O público também varia, dependendo das bandas que se apresentam. Um exemplo são as bandas de "rock de mina", muitas vezes lésbicas e bissexuais, que acabam atraindo uma quantidade grande de outras garotas que se relacionam entre si.
} 
de início da década de 1990, a boate foi inaugurada há dez anos e ficou famosa pelo seu after hours, etapa de funcionamento da casa que se estendia das 05h00 até às $10 \mathrm{h00}$ da manhã. Em 1998, "A Lôca" passa a abrigar uma das pouquíssimas noites dedicadas ao rock no cenário GLS, a festa Grind, que edita uma pequena publicação mensal de mesmo nome.

A indefinição do público e outros aspectos, como a sentença que acompanha o nome do projeto Grind: "rock project for mix people" 15 , indicam um claro interesse em estimular a convivência entre diversas identidade sexuais. Em campo, ouvi o dono do estabelecimento afirmar enfaticamente que se recusava a "entrar em lugar gay", e que tinha em sua casa "um público muito mais simpatizante do que G ou L". Um dos textos publicados em um número do Grindzine busca definir a atitude de se afastar da idéia de "gueto" e de "quebrar rótulos":

Havia uma festa. E era a única. Uma festa que transcendia o gueto e ousava mostrar novos rostos de uma comunidade que pensavam já ter sido explorada. (...) Afinal, como manter um rótulo diante de tanta coisa esquisita? Numa caverninha em uma rua qualquer de São Paulo, moços de coturno andavam de mãos dadas e se beijavam. Moços de moicano e moços com gel no cabelo também. (...) Mas a boa novidade não queria limites. Não queria um gueto, muito menos um rótulo. Adotou então o velho pensamento que acredita que as palauras aprisionam $e$ o "GLS" do começo virou "MIX". O público não era mais, e talvez nunca tenha sido, singular. Era plural. Não importava quem se quisesse beijar; sem as classificações, sem as definições de um gueto, ninguém se tornaria nada por causa de um beijo ou de uma amizade. As únicas palavras que se aceitaria seriam "Tolerância e respeito pela

\footnotetext{
${ }^{15}$ Apesar de ter sido popularizado através do site de mídia segmentada MixBrasil e ser comumente associado à sigla "GLS", o "mix" foge à nomeação das identidades a que se refere e foi adotado pela boate após um curto período em que se denominava "GLS".
} 
Sobre "guetos" e "rótulos"

diversidade" (e "diversidade", o Grind entendeu, era
plural). ${ }^{16}$

Assim, presenciei algumas situações na "A Lôca" em que as abordagens de flerte se faziam acompanhar da seguinte frase: "Você beija menino ou menina?", bem como também encontrei muitos freqüentadores que se autodefiniam como "bissexuais" ou "sem rótulos", e que diziam ir à casa noturna porque se sentiam "mais à vontade". ${ }^{17}$

A estrutura da casa, chamada de "caverninha" no trecho acima, remete à cena alternativa, com um porão todo pintado de preto que serve de pista de dança; decoração escura, com alguns instrumentos que lembram elementos $\mathrm{S} / \mathrm{M}$ (sadomasoquistas), como uma cadeira de tortura, posicionada logo à entrada; algumas máquinas de fliperama e os banheiros cujas portas não se fecham totalmente e de espaços muito reduzidos. É freqüentada, a exemplo da maioria dos outros estabelecimentos do mesmo tipo, por um público que se identifica com as variadas tendências $e$ gostos associados ao rock, gótico ou música eletrônica nas suas variações menos conhecidas. Normalmente, trata-se de um público bastante jovem, de 20 a 30 anos; que demonstra gosto especial pela prática de modificações corporais como o uso de piercings, alargadores nas orelhas, tatuagens e outros; que preza a androginia $e$ um certo trânsito entre convenções corporais $e$ comportamentais relacionadas a gênero: não é raro, por exemplo, ver rapazes de saia ou com os olhos pintados com lápis preto $e$ garotas de cabelo raspado; e que se diferencia pelo inusitado das roupas, muitas vezes pretas, e acessórios cuidadosamente selecionados, como os de referência fetichista.

${ }^{16}$ BABETTE, Fábio. Rock project for mix people. Grindzine, ano VII, n 74 , São Paulo, junho/2005:07, grifos meus.

${ }^{17}$ Algo a se confirmar em outros possíveis trabalhos é se a identidade de "bissexual" aparece mais comumente nestes espaços em que o trânsito e a indefinição entre as identidades de homossexual ou heterossexual aparentam ser mais aceitos. 
Embora esteja pontuando a impossibilidade de se aplicar sem mediações a categoria de gay ghetto ao cenário brasileiro, $e$ descrevendo algumas transformações que interpreto como centrais para uma configuração diferente do antigo "gueto" em direção a uma maior "abertura" e visibilidade, me parece que este ainda é visto, por uma parcela da população que o tem como um dos possíveis referenciais de lazer noturno, como um marcador de "rótulos" e difusor de estereótipos. A presença de estabelecimentos que se classificam a partir do princípio da diversidade sexual demonstra uma clara demanda por espaços que não se diferenciam pela orientação sexual de seus freqüentadores, sem que isto seja um modo de indicar uma destinação exclusiva a "heterossexuais". É discutível se isto significa "transcender o gueto" ou se, atrelada a esta concepção, não se criam novos "guetos" e preconceitos. O certo é que no interior do circuito mais "descolado", auto-identificado ou não como GLS, mas com uma grande presença de homossexuais ou bissexuais, também se constroem hierarquias e se operam classificações.

"Quase bonitos, quase modernos"

Podemos qualificar uma boa parcela dos freqüentadores dos espaços descritos no item anterior como "modernos" ou "descolados", categorias que têm ganhado espaço na mídia para definir um tipo de público atualizado no que diz respeito às referências internacionais de moda e estilo, que procura escapar de um visual considerado mainstream ou muito comum e que circula bastante pela vida noturna da cidade. Boa parte deste público costuma se espalhar pelos bares e "sinucas" das esquinas da Rua Augusta e apreciar a atmosfera "decadente" da região, tomada por prostitutas, pedintes e "botecos sujos", recorrendo a uma espécie de ressignificação do "lixo", transformado em "luxo", como atesta a recente moda de realização de festas em antigos bordéis da região. O centro da cidade também é uma opção 
Sobre "guetos" e "rótulos"

valorizada, nesse mesmo espírito, em que um equipamento é moldado ao gosto dos "modernos" 18 , sempre se diferenciando dos seus freqüentadores mais assíduos por meio da seleção cuidadosa de aspectos característicos de tais espaços que possam ser pinçados e remodelados de acordo com referências externas, acessíveis mediante o desenvolvimento de determinado estilo de vida e um meticuloso trabalho de constante "atualização cultural". Poderíamos dizer que são profissionais do "estilo de vida", pois, como lembra Featherstone,

em vez de adotarem um estilo de vida de maneira irrefletida, perante a tradição ou o hábito, transformam o estilo num projeto de vida e manifestam sua individualidade e senso de estilo na especificidade do conjunto de bens, roupas, práticas, experiências, aparências e disposições corporais destinados a compor um estilo de vida (Featherstone, 1995:123).

É importante ressaltar que a transformação do estilo "num projeto de vida", tal como notada pelo autor, é uma das dimensões possíveis de interpretação a partir do conceito de estilo de vida de Bourdieu, definido de forma mais ampla. Para Bourdieu,

o estilo de vida é um conjunto unitário de preferências distintivas que exprimem, na lógica específica de cada um dos subespaços simbólicos, mobília, vestimentas, linguagem ou héxis corporal, a mesma intenção expressiva, princípio da unidade de estilo que se entrega totalmente à intuição $e$ que a análise destrói ao recortá-lo em universos separados (Bourdieu, 1983:84).

\footnotetext{
${ }^{18}$ Sobre a relação com o centro da cidade, a produtora de uma casa noturna associada aos "modernos" e instalada próxima ao Elevado Costa e Silva, emite a seguinte opinião: "o Centro não é uma coisa óbvia. É a nossa cara: meio trash, meio under, meio gay. As pessoas descoladas acham o centro o máximo". Fonte: http://sampacentro.terra.com.br/textos.asp?id=503\&ph=33. Acesso: 20/06/2005
} 
Para Featherstone, os que têm no cultivo do estilo um "projeto de vida" são os "novos heróis da cultura de consumo". A diferença que parece ser importante de marcar neste caso é o fato dos "novos heróis" aos quais me refiro como "modernos" preferirem consumir aspectos relacionados ao underground, que contenham ares de novidade - $e$ às vezes de contestação $e$ liberação - ainda não popularizados. Ou, como já observei, elementos identificados com o "gosto popular" que possam ser de alguma forma recontextualizados ou valorizados como kitsch. Muito deste consumo liga-se às artes gráficas, à música (rock, pop, eletrônico, experimental), ao vídeo, à moda, ao design, e outras expressões de um tipo de produção artística que não é considerada tradicionalmente como "erudita", mas está associada à indústria cultural e a um processo de legitimação estética que aos poucos lhe atribui o status de "arte".

A ironia está na atuação dos "descolados" como intermediários culturais, lançando tendências e definindo gostos. Featherstone, de acordo com Bourdieu, considera como intermediários culturais os indivíduos possuidores de um capital econômico (definido pelo volume financeiro e de bens) e/ou capital cultural (definido pela composição de elementos) médio, posicionados entre os detentores do alto e do baixo capital econômico e cultural. Os grupos nesta posição intermediária teriam um papel decisivo na "produção do conjunto relacional das preferências estéticas de grupos específicos" (Featherstone, 1995:126). O autor também destaca o caráter dinâmico das relações entre os possuidores de alto e baixo capital, e as situações em que os grupos de baixo simplesmente "imitam ou usurpam os gostos dos grupos de cima, fazendo com que estes reajam adotando novos gostos que deverão restabelecer e conservar a distância original" (Id. ib.).

A abordagem de Bourdieu identifica os intermediários culturais como uma "nova pequena burguesia", que sentiria a necessidade de ser "mais do que é", educando-se o tempo todo a respeito do gosto, estilo e estilos de vida. Meus dados de pesquisa 
Sobre "guetos" e "rótulos"

e os limites de abrangência deste trabalho não me permitem ir tão longe a ponto de elaborar uma interpretação sociológica que dê conta das relações entre as posições de classe no campo da dinâmica cultural e a questão mais localizada dos "modernos". Assim, restrinjo-me apenas a caracterizar os "modernos" como intermediários culturais em virtude da sua atuação mais diretamente envolvida na produção simbólica, "especialmente na produção de imagens e informações celebradoras do estilo e dos estilos de vida" (Featherstone, 1995:121). Não me furto a marcar distinções de classe nesta dinâmica, mas me parece prematuro extrapolar estas distinções em direção a uma análise mais ampla no sentido de estabelecer de posições de classe no espaço social. Entretanto, a abordagem do trânsito de códigos e gostos na cultura de consumo é especialmente interessante na medida em que não recorre a uma afirmação da "implosão do espaço social" $e$ dos mecanismos de distinção justificada pela profusão $e$ instabilidade associada aos estilos e gostos, mas também não remete a uma fixidez que parece difícil de se comprovar quando observamos situações concretas. ${ }^{19}$

Fechado este parêntese, podemos dizer sobre a atuação dos "modernos" que, ao mesmo tempo em que valorizam um conhecimento reproduzido em pequena escala e restrito aos seus detentores considerados legítimos, também atraem a atenção da mídia e contribuem para a massificação de tendências que atuariam justamente como marcadores da sua diferença em relação ao mainstream e que também são assimiladas por grupos sociais que não pertencem a essa categoria como forma de distinção em relação a outros grupos. Uma situação em que essa dinâmica tornou-se particularmente explícita ocorreu quando o gosto por música eletrônica, por uma maneira de se vestir que valoriza o incomum e inusitado e pelas modificações corporais das quais o uso de piercings parece ter sido a que mais se popularizou - características dos primeiros clubbers chegou à

${ }^{19}$ A esse respeito, ver Sahlins, 2000. 
periferia na figura dos "cybermanos" 20 ou, como também se convencionou chamá-los, de modo bastante pejorativo, os "cyberfavela". ${ }^{21}$

Em grande parte jovens negros, apreciadores de drum'n'bass (uma das variações da música eletrônica), um tanto avessos à homossexualidade, com maquiagem exagerada, acessórios chamativos, roupas fluorescentes, e um sem número de piercings grudados ao corpo, os "cybermanos" destacavam-se em relação aos outros grupos de jovens dos bairros - como os pagodeiros que, segundo informante, são odiados pelos "cybermanos" - e tornavam-se um incômodo para os "legítimos clubbers". Erika Palomino, uma espécie de cronista da noite paulistana, narra o estranhamento causado pela entrada dos "cybermanos" na cena eletrônica e os mecanismos de diferenciação e segregação acionados neste contexto, operando classificações em termos de classe, cor e capital econômico e cultural:

de início, chamados pejorativamente de clubbers-favela pelo povo do Hell's, onde o apelido (superincorreto) surgiu num momento de popularização do clube. (...) No começo, as pessoas não sabem sequer como se referir a eles

\footnotetext{
${ }^{20}$ Utilizo neste trabalho a denominação "cybermano" para me referir a este grupo, porque me parece a denominação mais difundida e para marcar sua diferença em relação aos outros grupos de clubbers. Segundo informante, muitos destes jovens denominam a si mesmos como clubbers, simplesmente. De toda forma, pouco sei ao seu respeito, já que isto foge ao escopo deste trabalho, bastando-me por ora apenas marcar algumas possiveis diferenças e semelhanças entre eles e os clubbers ou "modernos" de início.

${ }^{21} \mathrm{O}$ caso descrito a seguir se deu em finais da década de 1990. Julgo importante trazê-lo à análise por ser um momento em que as dinâmicas aqui descritas explicitaram-se exemplarmente e porque poderíamos dizer que os "modernos", foco desta análise, são descendentes diretos dos clubbers, estabelecendo uma relação de continuidade com a cena clubber dos anos 1990. Embora a categoria clubber, justamente pela apropriação descrita aqui, não seja mais tão utilizada, poderíamos dizer que os primeiros clubbers se metamorfosearam nos "modernos" de hoje.
} 
Sobre "guetos" e "rótulos"

(clubbers de periferia, clubbers-flanelinha ou o igualmente pejorativo "trufa", gíria da noite para negro ou mulato). Cybermano aparece então como uma terminologia até mais carinhosa. (...) O Hell's termina em julho, deixando-os praticamente sem lar. Por sua vez, o Lov.e in Paradise (after-hours que sucede o Hell's em termos de badalação) seleciona a entrada do povo, cobrando um ingresso de 20 reais - caro para os manos. (...) Ao que parece, ninguém na cena quer se misturar (Palomino, 1999:245-246, grifo meu).

Ainda que os cybermanos tenham sido de alguma forma incorporados à cena eletrônica, mesmo que na periferia da cidade e em grandes festivais, o tipo de distinção que os segregava da cena "moderna" continua operando, mesmo que com as diferenças marcadas em tons mais amenos. Presenciei, num estabelecimento GLS de freqüência popular, uma situação em que uma garota que poderia ser qualificada como "moderna" ou "descolada", em atitude incomum, distanciou-se de seu pequeno grupo de pares para adentrar a aglomeração de pessoas no bar; minutos depois voltou, dizendo que pensara ter visto uma garota "quase-bonita" no lugar, referindo-se a uma possibilidade fracassada de flerte, devido à inadequação da "pretendente" aos seus padrões de "beleza".

A duas quadras dali, em um bar considerado um reduto de "modernos", a garota se sentiria mais à vontade para circular entre os presentes, em meio a tantas outras que se assemelhavam a ela e seu grupo e que poderiam ser qualificadas como "bonitas". O público dos dois espaços compartilhava muitos referenciais estéticos, mas a diferença estava no modo de combiná-los, sempre um pouco acima da nota, com acessórios ou roupas "fora do lugar" ou obtidas em lojas de produção altamente massificada ${ }^{22}$ entre os freqüentadores do estabelecimento mais popular.

${ }^{22}$ A apropriação das tendências "descoladas" por algumas cadeias de lojas de roupas e a aquisição de tais produtos por um público menos comprometido com outros elementos, que conformam uma atitude "underground" ou "alternativa", 
Assim, um "quase" que anuncia limites intransponíveis continua marcando e segmentando espaços e públicos na vida noturna associada a um público GLS ou "moderno", mediante distinções baseadas na adoção de determinados estilos de vida $e$ na manipulação correta de elementos em comum. Dessa maneira, gostos e referências estéticas comunicam-se entre diferentes públicos e vão sendo popularizados e incorporados de maneira própria em cada espaço, na medida em que novas distinções são criadas. Há, portanto, um jogo de diferenciações em cascata, num processo contínuo de expansão e demarcação de diferentes grupos sociais - muitas vezes definido através de um "quase" -, mediante a identificação com determinados gostos e estilos de vida. Afinal, na dinâmica que caracteriza a produção intencional e meticulosa de estilos de vida, embora haja um trânsito considerável de signos entre diversas categorias, um deslize pode ser considerado como indício de não-pertencimento. Nesse jogo, parece ainda valer a regra: "pars totalis, cada dimensão do estilo de vida simboliza todas as outras" (Bourdieu, 1983:84).

\section{Subjetividades, identidades e potencialidades}

Judith Butler, discutindo o termo "queer" e sua viabilidade do ponto de vista político, chamou a atenção para o fato de que os usos relacionados a categorias de identidade não podem ser totalmente previstos, o que nos remete à análise do emprego dessas categorias como contingentes, considerando as "relações de poder constitutivas e excludentes mediante as quais se formam os recursos discursivos contemporâneos" (Butler, 2002:319, tradução livre). A autora também nos alerta para as operações que podem habitar a própria produção de categorias, e para a necessidade de estarmos sempre atentos, no caso do termo "queer", para as categorias que os diversos usos do termo

é vista com desaprovação pelos "modernos legítimos", gerando o termo "modernos C\&A". 
Sobre "guetos" e "rótulos"

representam ou excluem, e em que situação. Assim, "queer" pode ser utilizado de modo patologizante ou, inversamente, contestador, o que remete não a uma oposição entre um uso reacionário do termo e um uso progressista, mas a um uso que progressivamente repete o termo reacionário na direção de criar um efeito de re-territorialização subversiva da norma.

Levando em conta tais considerações, Butler traz o exemplo de como palavras que constituem sujeitos podem ser utilizadas de forma a reafirmar a norma ou deslocá-la, dependendo do que se coloca em jogo (Butler, 1997). Avtar Brah relaciona tais questões a um processo de formação de identidades,

pelo qual a multiplicidade, contradição e instabilidade da subjetividade é significada como tendo coerência, continuidade, estabilidade; como tendo um núcleo - um núcleo em constante mudança, mas de qualquer maneira um núcleo - que a qualquer momento é enunciado como o "eu" (Brah, 2006:371).

Considerando a relação complexa entre subjetividade $e$ identidade, podemos dizer que discursos relacionados ao mercado são responsáveis pela cristalização de determinadas práticas $e$ subjetividades em identidades coletivas definidas, ainda que incipientes. Esse processo assume tons relacionados à ação política, quando tais subjetividades e práticas transformam-se numa identidade coletiva e ganham discursos específicos. Ainda, como afirma Brah, uma formação discursiva é sempre um lugar de poder,

e não há nenhum lugar de poder onde a dominação, subordinação, solidariedade e filiação baseadas em princípios igualitários, ou as condições de afinidade, convivialidade $e$ sociabilidade sejam produzidas $e$ asseguradas de uma vez por todas. Antes, o poder é constituído performativamente em práticas econômicas, políticas e culturais, e através delas. As subjetividades de 
Isadora Lins França

dominantes e dominados são produzidas nos interstícios desses múltiplos lugares de poder que se intersectam. A precisa interação desse poder em instituições e relações interpessoais específicas é difícil de prever. Mas se a prática é produtiva de poder, então a prática é também um meio de enfrentar as práticas opressivas do poder. Essa, em verdade, é a implicação do insight foucaultiano de que o discurso é prática (Id. ib.:373).

O movimento pelo qual as subjetividades são moldadas de forma a constituir identidades específicas e articuladas contra $e$ a partir de elementos vistos anteriormente como opressivos, ocupando lugares de poder $e$ dando origem a novas hierarquizações, foi o fio condutor ao qual procurei me ater no presente texto. Retomando o caminho aqui percorrido, observamos a emergência de diferentes categorias identitárias relacionadas à sexualidade na sua interface com consumo, classe e estilos de vida, de forma a localizá-las contextualmente: o termo GLS procurava demarcar, em sua origem, uma diferença em relação ao "gueto" - identificado com o centro de São Paulo e seus freqüentadores -, pressupondo uma maior disposição em relação à integração com heterossexuais "simpatizantes" $e$ conferindo ares de "modernidade" à cena gay da cidade. Com a sua apropriação por boa parte dos quais a intenção era se diferenciar, vemos o termo GLS também ser identificado como algo que delimita fronteiras entre hetero e homossexuais. Em oposição a GLS temos, então, a proposta de se "romper rótulos", em espaços caracterizados pela defesa da indefinição entre homo e heterossexual. "Rótulo", neste contexto, é um termo êmico que indica de maneira ampla um processo de classificação identitária em que se interpela ${ }^{23}$ determinados indivíduos de modo a produzir o seu reconhecimento como sujeitos a partir de um determinado esquema classificatório. Nesse caso, porém, percebemos a

${ }^{23}$ Utilizo aqui a noção de interpelação de Althusser (1999) - "Os aparelhos ideológicos de estado" - tal como relida por Butler (1997). 
Sobre "guetos" e "rótulos"

tentativa de construção de uma postura crítica sugerida pela recusa de um processo de classificação, em que o termo "rótulo" surge como denominador de um efeito reducionista. Tal recusa gera, por sua vez, novos pertencimentos e novas exclusões $e$ normatizações.

Desse modo, entra em cena a relação entre identidades sexuais e outros eixos de diferenciação social, como classe e estilo de vida, a partir de uma compreensão contextual a respeito da constituição de categorias relacionadas a identidades sexuais $e$ seus usos. No caso aqui analisado chama à atenção a dimensão assumida pela sexualidade como signo de diferenciação de classe e estilo de vida. Peter Fry (1982) já havia observado a convivência de diferentes sistemas classificatórios associados à homossexualidade à época do início do movimento homossexual no Brasil e a sua constituição em meio a diversos contextos relacionados a classe, raça, entre outros. Em contraposição a um sistema mais popular, organizado ao redor do par bicha/bofe, surgia um sistema de classificação pautado pela orientação do desejo em relação a alguém do mesmo sexo, mais próximo do movimento homossexual e da classe média. Assim, Fry já se adiantava à produção contemporânea que preconiza a necessidade de se construir uma abordagem interseccional em relação à sexualidade ${ }^{24}$, considerando suas relações com outros eixos de diferenciação (Facchini, 2006).

As relações entre variados eixos de diferenciação estão expostas aqui a partir de sua articulação por meio de espaços $e$ formas de sociabilidade relacionadas ao consumo. Automaticamente, por intermédio de tais práticas, são construídas barreiras aos que não partilham dos mesmos códigos $e$ experiências. Como já mencionado, o mercado segmentado relacionado à sexualidade tende a excluir sujeitos que não são tidos como consumidores, ou que não são tidos como consumidores de produtos específicos. Tal aspecto excludente,

${ }^{24}$ Refiro-me a autoras como Butler (2002), McClintock (1995) e Brah (2006). 
porém, não é privilégio do mercado, mas constitui a dinâmica mesma de qualquer formação discursiva que resulta na formação de identidades coletivas, o que significa que qualquer contestação de uma prática opressiva se dá no próprio interior dessa prática $e$ carrega também a possibilidade de gerar novas opressões (Brah, 2006). Em alguns momentos de sua obra, Foucault indica possíveis caminhos no sentido de contornar esse movimento contínuo que gera novas normatizações a partir do estabelecimento de identidades, defendendo uma "construção radical da subjetividade" 25 que contrariasse a hegemonia histórica do sujeito jurídico e seus efeitos de verdade (Butler, 1997:100), ou uma estética da existência, "alternativa a formas de relacionamento socialmente prescritas e institucionalizadas" (Miskolci, 2006:229).

Para Stuart Hall, nos últimos trabalhos de Foucault é possível perceber um

avanço considerável ao mostrar como isso [que a constituição dos sujeitos] se dá, em conexão com práticas discursivas historicamente específicas, com a auto-regulação normativa e com tecnologias do eu. A questão que fica é se nós também, precisamos, por assim dizer, diminuir o fosso entre os dois domínios, isto é, se precisamos de uma teoria que descreva quais são os mecanismos pelos quais os indivíduos considerados como sujeitos se identificam (ou não se identificam) com as posições para as quais são convocados; que descreva de que forma eles moldam, estilizam, produzem e 'exercem' essas posições; que explique por que eles não o fazem completamente, de uma só vez e por todo o tempo, e por que alguns nunca o fazem, ou estão em um processo constante, agonístico, de luta com as regras normativas ou regulativas com as quais se confrontam e pelas quais regulam a si mesmos - fazendo-

${ }^{25}$ No original, um "radical making of subjectivity". Na tradução, perde-se um pouco a idéia de um fazer contínuo que a expressão "making of" sugere. 
Sobre "guetos" e "rótulos"

lhes resistência, negociando-as ou acomodando-as (Hall, 2003:126).

A perspectiva de Butler incorpora o trabalho de Foucault ao reconhecer a importância das formações discursivas no processo de construção de identidades e subjetividades, mas dá um passo além na direção de diminuir o fosso identificado por Hall quando procura explorar a dimensão da agência dos sujeitos dada pelo próprio processo de subjetivação. A pergunta transforma-se, então, de "como criar novas subjetividades ou como recusar identidades construídas no bojo de um discurso hegemônico" para "como explicar os mecanismos pelos quais os sujeitos se reconhecem em determinadas identidades como sujeitos", o que permanece ainda sem resposta, a despeito dos esforços dos autores aqui utilizados para produzir avanços nesse sentido.

Butler (1997), citando Giorgio Agamben, lembra que o desejo de "ser" simplesmente, o desejo de reconhecimento e o processo de subjetivação não pode ser entendido como algo que elimine qualquer experiência ética ou que defina uma essência humana que mina a idéia de existência como potencialidade. Assim, poderíamos "reler 'ser' como precisamente a potencialidade que permanece inexaurida por qualquer interpelação particular". Neste trabalho, mais do que investigar supostas subjetividades resistentes a constrangimentos hegemônicos, me limitei a utilizar um corpo teórico específico de modo a guiar minha análise de como diferentes subjetividades surgem $e$ são negociadas no âmbito do mercado como identidades, explorando um movimento ambíguo de inclusão e, ao mesmo tempo, de exclusão na constituição de categorias pautadas por determinada identidade sexual ou mesmo pela recusa da orientação sexual como um eixo de definição. Embora nesse complexo jogo entre subjetividades $e$ identidades transpareçam todos os efeitos normatizadores relacionados à cristalização de identidades e ao mercado segmentado, em meio aos seus caminhos tortuosos, espero ter sido possível vislumbrar a 
Isadora Lins França

idéia da existência como potencialidade, mesmo que mais ou menos delimitada por determinadas relações sociais e pelos constrangimentos daí advindos.

\section{Referências bibliográficas}

AlthUSSER, Louis. Sobre a Reprodução. São Paulo, Vozes, 1999.

BOURDIEU, Pierre. Gostos de classe e estilo de vida. In: OrTIz, Renato. (org) Pierre Bourdieu: sociologia. São Paulo, Ática, 1983.

BRAH, Avtar. Diferença, diversidade, diferenciação. Cadernos Pagu (26), Campinas-SP, Núcleo de Estudos de Gênero-Pagu/Unicamp, 2006, pp.329-376.

BUTLER, Judith. Reescinificación de lo universal: hegemonía y límites del formalismo. In: BUTLER, J.; LACLAU, Ernesto; ZIZEK, Slavoj. Contingencia, hegemonía, universalidad: diálogos contemporáneos em la izquierda. Buenos Aires, Fondo de Cultura Econômica, 2003a.

Problemas de gênero: feminismo e subversão da identidade. Rio de Janeiro, Civilização Brasileira, 2003b.

Cuerpos que importan - Sobre os límites materiales y discursivos del "sexo". Buenos Aires/Barcelona/México, Paidós, 2002.

The Psychic Life of Power - Theories in Subjection. California, Stanford, 1997.

CALIL, Marinês Antunes. O retrato do Nation Disco Club: os neodândis no final dos anos 80. In: MAGNANI, José Carlos Cantor; TORRES, Lilian de Lucca. Na metrópole: textos de antropologia urbana. São Paulo, Edusp, 2000.

DOUGLAS, Mary; ISHERWOOD, Baron. O mundo dos bens: para uma antropologia do consumo. Rio de Janeiro, Editora UFRJ, 2004.

FACCHINI, Regina. Entrecruzando diferenças: corporalidade e identidade entre mulheres com práticas homoeróticas na Grande São Paulo. Comunicação apresentada na $25^{a}$ RBA - Reunião Brasileira de Antropologia, Goiânia, 2006.

"Sopa de letrinhas?" Movimento homossexual e produção de identidades coletivas nos anos 90. Rio de Janeiro, Garamond, 2005. 
Sobre "guetos" e "rótulos"

Featherstone, Mike. Cultura de Consumo e Pós-Modernismo. São Paulo, Studio Nobel, 1995.

FouCAult, Michel. História da Sexualidade I. A vontade de Saber. Rio de Janeiro, Graal, 1979.

FRANÇA, Isadora Lins. Cercas e pontes. O movimento GLBT e o mercado GLS na cidade de São Paulo. Dissertação de mestrado, Antropologia Social, USP, 2006a.

. "Cada macaco no seu galho?": arranjos de poder, políticas

identitárias e segmentação de mercado no movimento homossexual. Revista Brasileira de Ciências Sociais (21:60), São Paulo, ANPOCS, 2006b, pp.103-115.

FRY, Peter. Para inglês ver. Identidade e política na cultura brasileira. Rio de Janeiro, Zahar, 1982.

GALVÃo, Jane. Aids no Brasil: a agenda de construção de uma epidemia. Rio de Janeiro/São Paulo, ABIA/Editora 34, 2000.

GAMSON, Joshua; Moon, Dawne. The sociology of sexualities: queer and beyond. Annual Review of Sociology (30), 2004, pp.47-64.

GIFFNEY, Noren. Denormatizing queer theory: more than (simply) gay and lesbian studies. Feminist Theory (5), 2004, pp.73-78.

GONTIJO, Fabiano. Rei Momo e o arco-íris: etnografia das imagens identitárias homossexuais no carnaval do Rio de Janeiro. In: BRANDÃo, Saulo Cunha de Serpa; LIMA, Maria Auxiliadora Ferreira. (orgs.) Ensaios Reunidos. Teresina, Halley, 2005.

GREEN, James. "Mais amor e mais tesão": a construção de um movimento brasileiro de gays, lésbicas e travestis. Cadernos Pagu (15), Campinas-SP, Núcleo de Estudos de Gênero-Pagu/Unicamp, 2000, pp.86-102.

HALL, Stuart. Da diáspora: identidades e mediações culturais. Belo Horizonte, Editora UFMG, 2003.

HARAWAY, Donna. Gênero para um dicionário marxista: a política sexual de uma palavra. Cadernos pagu (22), Campinas-SP, Núcleo de Estudos de Gênero-Pagu/Unicamp, 2004, pp.201-246.

JAGOSE, Annamarie. Queer theory. An introduction. New York University Press, 1996. 
MCCLINTOCK, Anne. Imperial Leather: Race, Gender, and Sexuality in the Colonial Contest. New York, Routledge,1995.

MILLER, Daniel. Teoria das compras: o que orienta as escolhas dos consumidores. São Paulo, Studio Nobel, 2000.

Consumption as the vanguard of history: a polemic by way of an introduction. In: MILLER, D. (org.) Acknowledging consumption: a review of new studies. New York, Routledge, 1995, pp.1-57.

MISKOLCI, Richard. Existência e pânico moral. In: RAGO, Margareth e Veiga-Neto, Alfredo. (orgs.) Figuras de Foucault. Porto Alegre, Autêntica, 2006, pp.227-238.

PAlOMino, Erika. Babado forte: moda, música, noite. São Paulo, Mandarim, 1999.

PARKER, Richard G. Sexo entre homens: consciência da AIDS e comportamento sexual entre os homens homossexuais e bissexuais no Brasil. In: PARKER, R. et alli. (orgs.) A Aids no Brasil. Rio de Janeiro, Relume Dumará/ABIA/IMS/UERJ, 1994, pp.129-149.

Perlongher, Nestor. O que é Aids. São Paulo, Brasiliense, 1987.

Piscitelli, A.; Gregori, M. F.; Carrara, S. (orgs.) Sexualidade e saberes: convenções e fronteiras. Rio de Janeiro, Garamond, 2004.

SAHLINS, Marshall. Cultura e Razão Prática. Rio de Janeiro, Jorge Zahar, 1979.

SimÕES, Júlio Assis e FrANÇA, Isadora Lins. Do Gueto ao mercado. In: GREEN, James Naylor; TRINDADE, Ronaldo. (orgs.) Homossexualismo em São Paulo e outros escritos. São Paulo, Editora Unesp, 2005.

Trevisan, João Silvério. Devassos no Paraíso. Homossexualidade no Brasil da colônia à atualidade. Rio de Janeiro, Record, 2000.

VEBLEN, Thorstein. A teoria da classe ociosa. São Paulo, Pioneira, 1965. 